\title{
Analisis Sistem Termal Pada Double Drum Water Tube Boiler Untuk Memproduksi Superheated Pengaruh Rasio Udara Bahan Bakar Gas
}

\author{
Daffa Alidina $^{* 1}$, Ericx Arga ${ }^{2}$, K.A Ridwan ${ }^{3}$, Zurohaina $^{4}$, Adi Syakdani ${ }^{5}$ \\ 1,2,3,4,5Program Studi Teknik Energi, JurusanTeknik Kimia, \\ Politeknik Negeri Sriwijaya, Indonesia \\ Email: ${ }^{1}$ m.daffa1199@gmail.com, ${ }^{2}$ ericxargav@gmail.com,
}

\begin{abstract}
Abstrak
Water Tube Boiler adalah komponen alat yang dirancang untuk membentuk uap air yang memiliki tekanan dimana produksi uap pada ketel uap didapat dari pemanasan air yang uap nya dipampat menjadi bertekanan dan memiliki panas yang bersuhu tinggi. Proses pengapian terjadi pada bagian luar pipa yang lalu panas tersebut memanaskan pipa yang berisi air yang sebelumnya telah dikondisikan melalui economizer. Steam yang telah terbentuk kemudian dikumpulkan didalam wadah yang disebut steamdrum. Tekanan atau panas ini digunakan menjadi media pemanas, pengering, serta pembangkit listrik. Kualitas steam boiler ditentukan melaui desain awal boiler, kualitas air umpan, sirkulasi uap, tekanan boiler, temperatur, dan efisiensi boiler. Untuk menerima kualitas steam yang baik, ditentukan menggunakan syarat input bahan bakar serta udara pada proses pembakaran yang dimana bahan bakar yang dipergunakan wajib memiliki nilai kalor lebih besar supaya kemampuan udara bercampur dengan bahan bakar akan lebih baik. Perbandingan udara bahan bakar pada penelitian mengenai boiler menggunakan sistem double drum water tube boiler dilakukan pengamatan menggunakan dampak rasio udara divariasikan untuk mengetahui kualitas steam yang didapatkan. Adapun rasio yang digunakan yaitu: 129,$32 ; 264,93 ; 341,27 ; 361,48$ dan 441,81 serta flow bahan bakar sebesar 1,49 kilogram/jam. Tujuannya untuk mengetahui apakah efek rasio udara bahan bakar mempengaruhi kualitas steam yang dihasilkan.
\end{abstract}

Kata kunci: Bahan Bakar Gas, Boiler, Rasio Udara Bahan Bakar, Steam.

\section{Analysis of The Thermal System on A Double Drum Water Tube Boiler for Producing Superheated The Effect of The Air Fuel Gas Ratio}

\begin{abstract}
Water Tube Boiler is a component of a device designed to form water vapor that has pressure where the production of steam in a steam boiler is obtained from heating water whose steam is compressed to be pressurized and has high temperature heat. The ignition process occurs on the outside of the pipe, then the heat heats the pipe containing water that has previously been conditioned through the economizer. The steam that has been formed is then collected in a container called a steamdrum. This pressure or heat is used as a heating medium, dryers, and power plants. Steam boiler quality is determined through the initial boiler design, feed water quality, steam circulation, boiler pressure, temperature, and boiler efficiency. To receive good steam quality, it is determined using the conditions for input of fuel and air in the combustion process in which the fuel used must have a greater heating value so that the ability of air to mix with fuel will be better. Air-fuel comparisons in research on boilers using a double drum water tube boiler system were observed using the impact of varying air ratios to determine the quality of the steam obtained. The ratios used are: 129.32; 264.93; 341.27; 361.48 and 441.81 and fuel flow of 1.49 kilograms/hour. The aim is to determine whether the effect of the air-fuel ratio affects the quality of the steam produced.
\end{abstract}

Keywords: Air Fuel Rasio, Boiler, Gas Fuel, Steam.

\section{PENDAHULUAN}

Pada lingkungan pabrik keperluan uap air atau steam artinya hal yg sangat krusial, serta tak dipisahkan bagi aktivitas atau langkah produksi. Tuntunan buat mendapatkan sumber uap air secara praktis, efisien dan dapat memenuhi keperluan uap air dalam kapasitas yang diinginkan. Boiler ialah suatu alat berbentuk bajan tertutup yang dipergunakan buat memproduksi uap [1]. Boiler dibidang industri merupakan solusi pemenuhan kebutuhan 
untuk proses produksi, pemanfaatan uap panas steam yang dimanfaatkan energi panasnya untuk proses produksi tahu, laundry, garmen dan pembangkit listrik [2].

Di ketel pipa air, air umpan boiler berkecimpung melalui pipa-pipa masuk ke pada tangki, uap tercipta karena energi panas ditransfer dari luar pipa yg dipanaskan oleh gas pembakaran yg terjadi didaerah cairan di dalam drum. Sebagai akibatnya ketel yg telah sangat berkembang.ketel pipa air biasanya dirancang dengan tekanan sangat tinggi yaitu hingga lebih dari 100 bar dan memiliki daya muat uap antara 4.500-12.00 kg/jam [3]. di prinsip kerja boiler terjadinya pembakaran artinya asal bahan bakar sebagai akibatnya menimbulkan panas. Umumnya boiler memakai bahan bakar cair (residu, solar), padat (batubara), atau gas [4]. Panas berasal bahan bakar lalu digunakan buat memasak air di dalam boiler sebagai akibatnya air bisa mendidih menghasilkan uap atau steam sehingga terjadinya tekanan dalam boiler. Hasil dari steam itu mengandung tenaga potensial yang nantinya tenaga steam tersebut masuk ke dalam pesawat uap dan dirubah menjadi tenaga mekanik [5].

Aspek krusial sebab keterkaitan terhadap efisiensinya. Faktor yang mempengarui effisiensi boiler pada umumnya adalah desain awal boiler, kualitas air umpan, kualitas udara, kualitas Untuk bakar yang digunakan, kualitas komponen mengoptimalkan pemanfaatan tenaga secara lebih mudah dan berhemat porto produksi terhadap pemakaian bahan bakar maka analisis tentang pengembangan performa pada boiler artinya bahan utama dan komponen penunjang boiler serta sistem kontrol yang terpasang. Karakteristik energi kerja asal suatu alat bisa dikatakan menjadi efisien jika kinerja kerja atau taraf buat kerja boiler diperoleh asal kesetaraan antara tenaga yg diubah kea tau diserap sang cairan kerja didalam ketel menggunakan memasukan tenaga kimia berasal bahan bakar. kemampuan boiler umumnya berkisaran antara $70 \%$ sampai $90 \%$ [6].

Produk steam boiler ini sudah dapat dilihat dari Henan Kaifeng Swet Boiler Co. Ltd China pada tahun 2016, yang menggunakan sistem double drum vertikal dengan efisiensi termal sebesar $61.1 \%$ dan nilai penguapan mencapai 10 ton/hour. Ini sudah bisa dikatakan bagus, namun masih ada sedikit kekurangan, yaitu arah tube yang sangat vertikal antara steam drum dengan boiling drum, kemudian yang harus diperbaiki adalah dengan mengubah arah tube menjadi kemiringan tube dibuat $65^{\circ}$ bertujuan untuk mengurangi gaya gravitasi sehingga kecepatan penguapan akan lebih baik dibandingkan dengan vertikal tube [7].

[8] melakukan penelitian "mengenai boiler dengan menggunakan sistem cross section untuk memproduksi steam dengan tekanan 5 bar dengan rasio udara bahan bakar 28.89, 29.16, 29.44, 29.71 dan 19.99 kondisi yang optimal terdapat pada rasio ke 4 udara bahan bakar yaitu 29.71 dengan nilai efisiensi termal boiler sebesar $61.27 \%$ ".

Maka dari penelitian kali ini kami akan upgrade dari sistem boiler tersebut dengan dilakukan pada sistem injection boiler feed water dan sistem secondary udara pembakaran dan sistem terisolasi menggunakan burner sistem tertutup. Pada sistem injection boiler feed water dilakukan perubahan sistem pemompaan jenis torak yang tahan pada tekanan arus balik panas. Untuk sistem secondary udara pembakaran akan dipasang blower dengan laju pemasokan yang terkontrol dan burner dengan sistem tertutup.

Asal akibat analisis yg diperlukan nantinya bisa dilakukan tindak lanjut yg berdampak di pengembangan performa kerja boiler serta otomatis pengembangan holistik unit boiler yg ditinjau berasal "pengaruh rasio udara bahan bakar gas terhadap lahu produksi superheated steam per satuan waktu steady state proses".

Berdasarkan uraian diatas, penulis merasa tetarik untuk membuat dan membahas mengenai "Analisis Sistem Termal Pada Double Drum Water Tube Boiler untuk memproduksi superheated steam pengaruh rasio udara bahan bakar gas" sebagai judul penelitian penulis.

\section{METODE PENELITIAN}

\subsection{Waktu dan Tempat}

Riset dilaksanakan di bulan Maret 2021 sampai bulan Juni 2021 di Laboratorium Program Studi Teknik Energi Jurusan Teknik Kimia Politeknik Negeri Sriwijaya.

\subsection{Pendekatan Desain Fungsional}

Rancang bangun upgrade ketel pipa air terdiri asal delapan komponen primer yaitu steam drum, drum air, pipa air, furnace, superheater, pump, kompresor, dan blower.

\subsection{Pendekatan Desain struktural}

Ketel pipa air didesain menggunakan beberapa komponen yg bergabung sebagai suatu sistem terintegrasi. Komponen yg paling primer ialah duah buah drum (drum air serta drum uap) yg terhubung menggunakan water tube serta superheater menjadi daerah terjadinya proses pemanasan air serta uap air. Bahan bangun drum tersebut dari baja karbon. Tubing superheated dan water tube terbuat dari pipa carbon SCN 40 yang tahan pada 
kondisi suhu dan tekanan tinggi. Pompa yang berfungsi untuk mengumpankan bahan baku air merupakan pompa Sentrifugal dengan konsumsi daya motor pompa $0.34 \mathrm{kw}$. Suplai udara primer pembakaran pada burner berasal dari kompresor udara dengan kapasitas tekanan 8 bar. Secara rinci kontruksi sistem boiler bisa dilihat digambar dibawah ini:

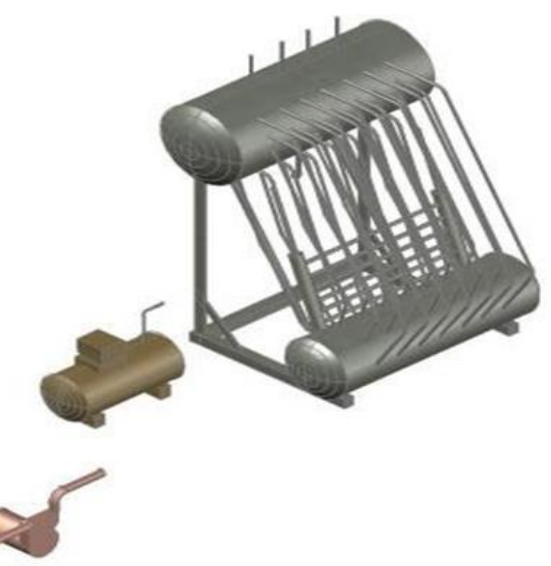

Gambar 1. Perangkat Water Tube Boiler

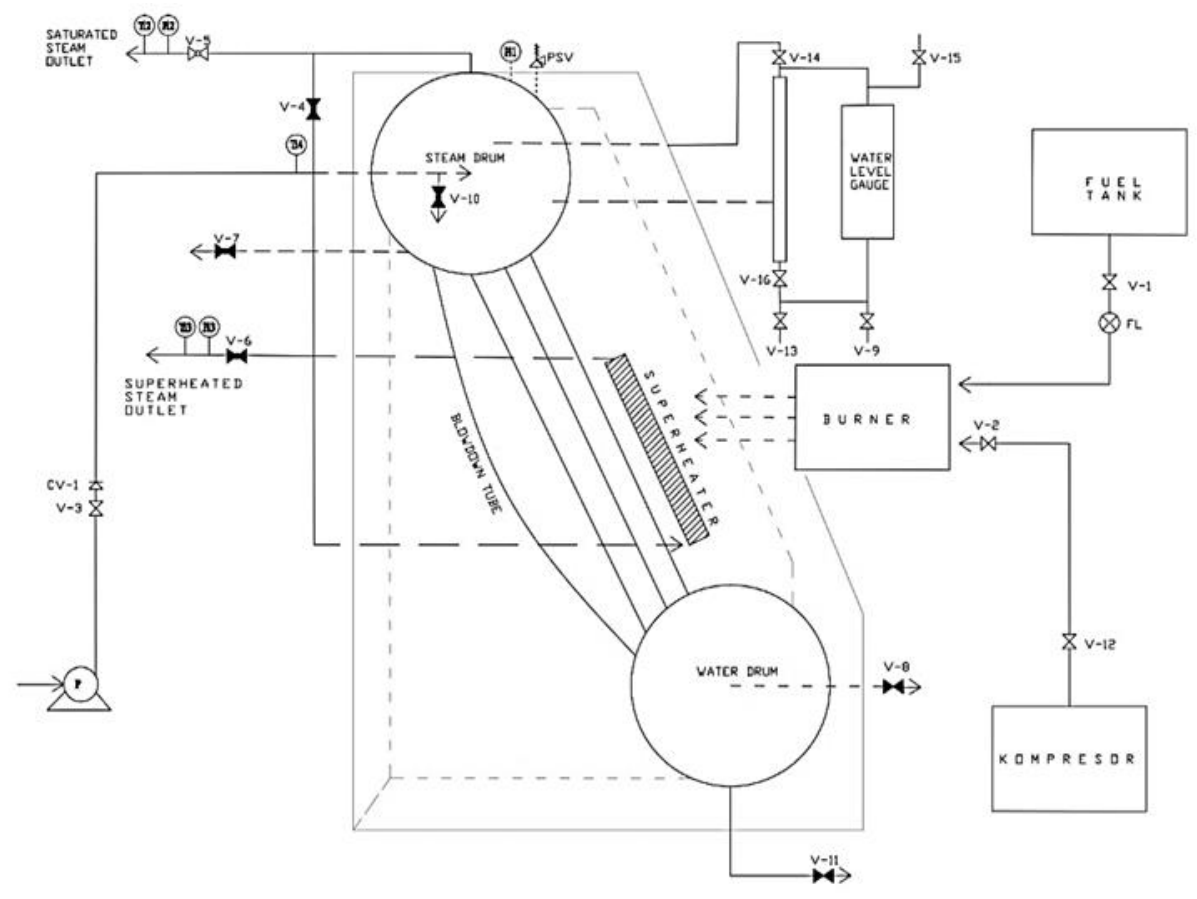

Gambar 2. Gambar Teknik Rancang Bangun Water Tube Boiler Setelah di Upgrade

Dari Gambar 2. Bahwa Rancang Bangun Water Tube Boiler setelah di upgrade sudah menggunakan sistem control level air, sistem injection feed water, sistem secondary udara. Sistem control level air pada steam drum bertujuan agar air didalam water level gauge tenang dan mudah terbaca oleh alat water level gauge pada saat proses berjalan. Sistem injection feed water bertujuan pergantian pompa yang tahan tekanan balik dan tahan panas, pompa diganti dengan spesifikasi tekanan yang lebih besar. Sistem secondary udara bertujuan untuk laju pemasokan udara lebih terkontrol.

Dari gambar 3 dimana terdapat tangki bahan bakar, komproses, burner, furnace. Fungsi tangki bahan bakar ialah wadah beserta pensuplai bahan bakar yang diperlukan untuk proses pembakaran, proses nya dengan membuka valve (V-01) dan melakukan pengukuran besar atau kecil api sesuai yang dibutuhkan. Kompresor berfungsi untuk memampatkan fluida gas atau meningkatkan tekanan udara, proses nya menghidupkan kompresor, menutup valve evluen hingga tekanan kompresor sebesar 8 bar, membuka valve evluen berdasarkan 
udara suplai dari rasio udara bahan bakar dan membuka valve (V-02) kemudian mengatur kecepatan udara sesuai dengan rasio udara bahan bakar. Burner merupakan alat untuk menghasilkan sumber api bagi boiler, yaitu dengan cara membakar campuran bahan bakar (gas). Furnace atau sering disebut sebagai tungku pembakaran tempat terjadinya pembakaran atau pemanasan hingga suhu yang tinggi.

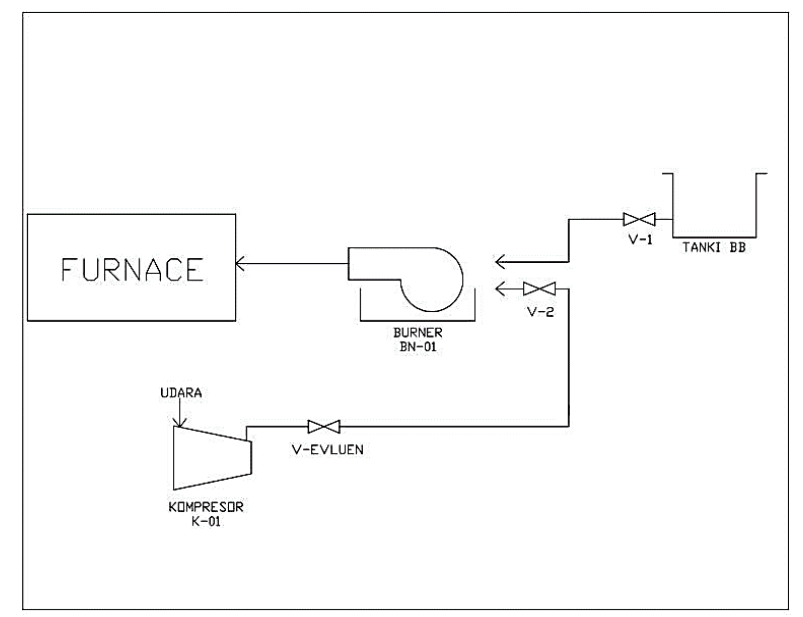

Gambar 3. Skema Rasio Udara Bahan Bakar

\subsection{Alat dan Bahan}

Adapun alat yang digunakan dalam upgrade boiler, diantaranya ialah gerinda listrik, bor listrik, alat las listrik, kunci pas set, kunci ring pas set, gergaji besi, satu set alat ulir. Peralatan laboratorium yang digunakan anomometer tipe digital wind speed GM816, Thermogan tipe infrared TM990 $\left(200^{\circ} \mathrm{C}-2150^{\circ} \mathrm{C}\right)$.

Adapun bahan baku yang akan digunakan untuk melakukan percobaan yaitu air, berupa bahan baku yang akan digunakan, solar, gas LPG, udara dari kompresor.

\subsection{Perlakuan dan Rancangan Percobaan}

Penelitian yang dilakukan dengan menggunakan prototype boiler sistem non steady state / steady state dengan menggunakan double drum yang masing-masing memiliki fungsi yakni sebagai feed water drum dan steam drum untuk pengolahan air umpan boiler menjadi steam yang berkualitas saturated maupun superheated memiliki beberapa variabel yang diambil antara lain variabel tetap dan berubah 129.32, 264.93, 341.27, 361.48, dan 441,81. Dengan udara excess sebesar 5\%, 14\%, 20\%, 21\%, dan $26 \%$.

\subsection{Prosedur Percobaan}

Tahapan prosedur penelitian yaitu persiapan hingga pengoperasian. Dengan menggunakan standar pengoperasian berdasarkan metode pasa ASME PD 769 sectin VI [9].

\section{HASIL DAN PEMBAHASAN}

Pada penelitian kali ini dirancang ketel bentuk pipa air dengan menggunakan sistem Double Drum Water Tube Boiler yg ialah memakai dua drum serta pipa di boiler terancang secara melintang menggunakan tujuan memperbesar area pipa sebagai akibatnya luas area perpindahan panas di boiler sebagai lebih besar serta memakai kemiringan di pipa $65^{\circ}$ menggunakan tujuan supaya meningkatkan kecepatan penguapan di molekul air [10]. Bahan bakar yg dipergunakan di riset ini ialah gas LPG $12 \mathrm{~kg}$ buat menerima proses pembakaran tepat, maka diharapkan udara pembakaran. Berikut grafik korelasi antara rasio udara bahan bakar terhadap temperature, entalpi, tekanan superheated steam dan effisiensi termal dan heat loss superheated steam.

\subsection{Pengaruh Rasio Udara Bahan Bakar Terhadap Temperatur Superheated Steam}

Berikut merupakan grafik hubungan antara pengaruh rasio udara bahan bakar terhadap temperature superheated steam terlihat pada Gambar 4.

Dari Gambar 4. Bahwa di rasio ke 5 menggunakan jumlah rasio udara bahan bakar 441.81 menggunakan temperatur superheated steam $200^{\circ} \mathrm{C}$ sudah mencapai tekanan 5.1 bar serta steam 15.9 kilogram/jam yg diinginkan. Galat satu faktor yg mempengaruhi proses kecepatan pembakaran yaitu temperature. Superheated 
steam yaitu kondisi air serta steam bisa berada secara bersamaan di aneka macam tekanan. pada kurva ini keduanya akan berada di suhu jenuh. Superheated steam atau uap jenuh atau pemanasan ulang di boiler dimana biasanya titik kritis saturated steam berada pada suhu $374^{\circ} \mathrm{C}$ dan dipanaskan kembali hingga sampai titik kritis $500^{\circ} \mathrm{C}$ menghasilkan superheated steam. di rasio udara bahan bakar ke-1 menggunakan jumlah rasio udara bahan bakar 129.32 menggunakan temperature superheated steam $167^{\circ} \mathrm{C}$ menggunakan tekanan 3.5 bar serta steam $14.5 \mathrm{~kg} / \mathrm{jam}$ belum mampu dikatakan optimal. bila dibandingkan di rasio udara bahan bakar ke-lima dengan jumla udara 441,81 menggunakan tekanan 5.1 bar serta steam 15.9 kilogram/jam belum dikatakan optimal walaupun temperatur superheated steam, tekanan serta steam yang didapatkan telah sinkron target. Hal ini dikarenakan jumlah rasio udara bahan bakar yg dikeluarkan terbuang sia-sia dibandingkan dengan rasio bahan bakar ke-4 hanya 361.48 temperatur superheated steam, tekanan, serta steam yang dihasilkan sudah mencapai sasaran optimal.

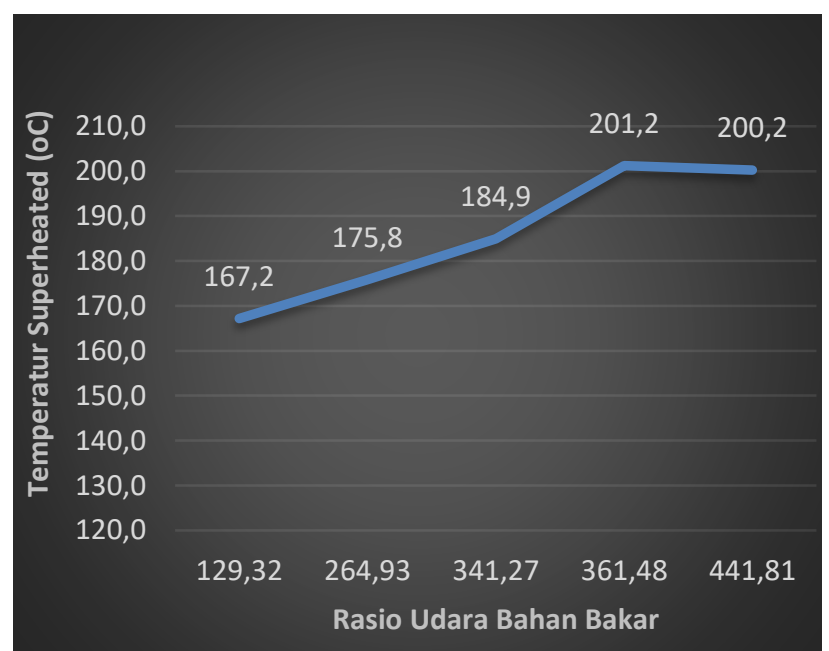

Gambar 4. Grafik Hubungan Rasio Udara Bahan Bakar Terhadap Temperatur Superheated Steam $\left({ }^{\circ} \mathrm{C}\right)$

\subsection{Pengaruh Rasio Udara Bahan Bakar Terhadap Entalpi Superheated Steam (kj/kg)}

Berikut merupakan grafik hubungan antara pengaruh rasio udara bahan bakar terhadap entalpi terlihat pada Gambar 5.

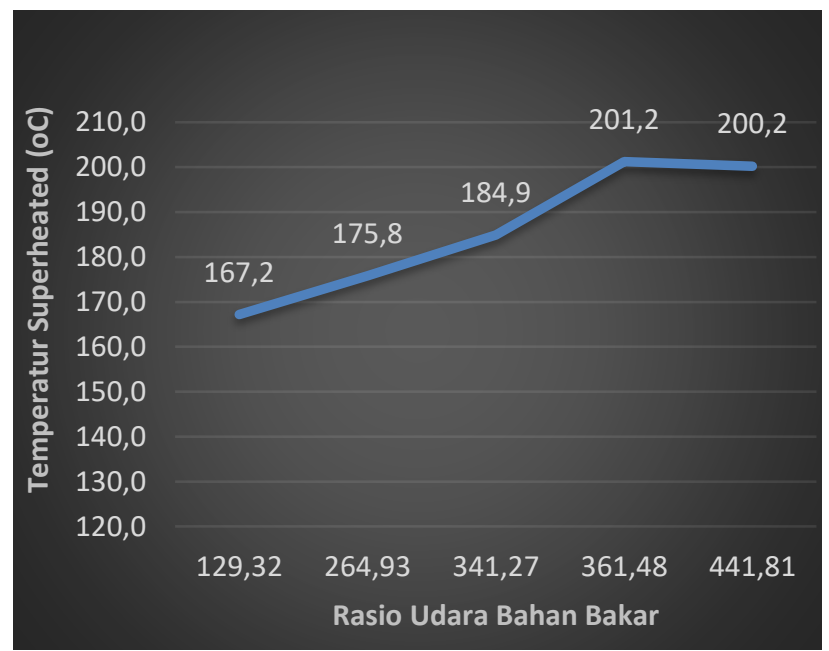

Gambar 5. Hubungan Rasio Udara/BB Terhadap Entalpi Steam (kj/kg)

Dari gambar diatas bisa dicermati di rasio udara/BB ke-1 menggunakan jumlah rasio udara/BB 129.32 menggunakan entalpi superheated steam yg dihasilkan yaitu $2788.1 \mathrm{kj} / \mathrm{kg}$ dibandingkan di rasio ke-4 menggunakan jumlah rasio udara/BB 361.48 dengan entalpi superheated steam yang didapatkan yaitu 2855.4 $\mathrm{kj} / \mathrm{kg}$. hal ini di karenakan tekanan pada rasio ke-1 lebih kecil dibandingkan dengan rasio ke-4 dengan tekanan optimal yaitu 5.2 bar lebih optimal dibandingkan dengan rasio ke-5 dengan entalpi superheated steam yang 
didapatkan yaitu 2853,2 kj/kg karena terjadi penurunan energi. Entalpi didefinisikan menjadi jumlah energi pada ditambah produk volune serta tekanan panas berasal suatu zat, secara awam entalpi merupakan sifat suatu zat, seperti tekanan, suhu dan volume.

\subsection{Pengaruh Rasio Udara Bahan Bakar Terhadap Tekanan Superheated Steam (bar)}

Berikut merupakan grafik hubungan antara pengaruh rasio udara bahan bakar terhadap tekanan superheated steam terlihat pada Gambar 6.

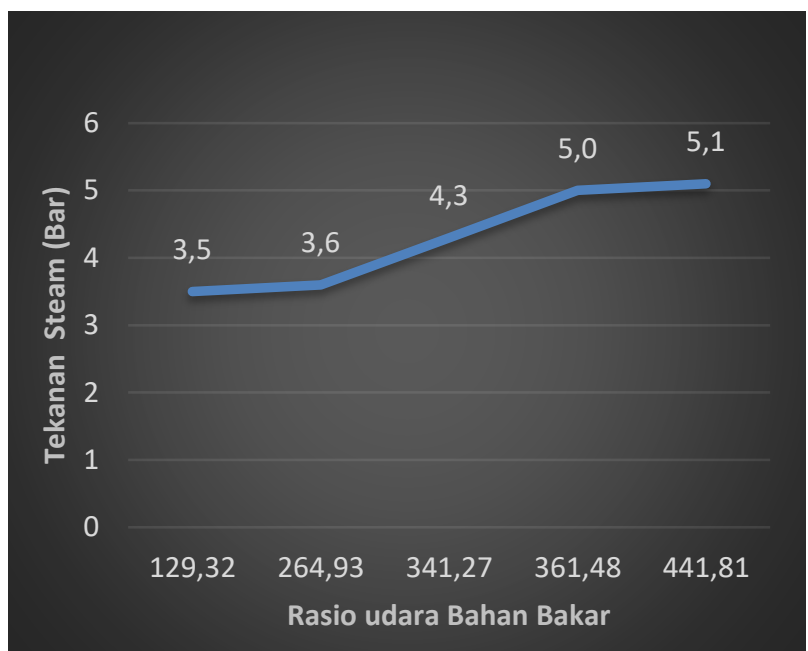

Gambar 6. Hubungan Rasio Udara/BB Terhadap Tekanan Superheated Steam

Dari gambar pada atas bisa ditinjau di rasio udara/BB ke-1 dengan tekanan superheated steam yang didapatkan yaitu 3.5 bar dibandingkan pada rasio ke-4 tekanan superheated steam yang didapatkan yaitu 5.0 bar. Hal ini dikarenakan temperatur pada rasio ke-1 lebih kecil dibandingkan pada rasio ke-4 dengan tekanan optimal yaitu 5 bar.

\subsection{Pengaruh Rasio Udara Bahan Bakar Terhadap Effisiensi Termal Boiler (\%)}

Berikut merupakan grafik hubugan antara pengaruh rasio udara bahan bakar terhadap effisiensi termal boiler terlihat pada Gambar 7 dan Gambar 8.

Termal boiler $67.59 \%$ dengan kehilangan panas yaitu $32.41 \%$ didapatkan pada rasio 441.81 dengan udara excess $26 \%$ tekanan 5.1 bar, temperatur superheated steam $200^{\circ} \mathrm{C}$, temperatur flame $760^{\circ} \mathrm{C}$ karena pada rasio ke5 terjadi kenaikan efisiensi dan kehilangan panas menurun sehingga pada proses pembakaran terjadi dengan sempurna karena kebanyakan panas termanfaatkan dari pada keluaran terbuang. Sehingga dikatakan optimal dengan apa yang di ingin dicapai pada penelitian ini.

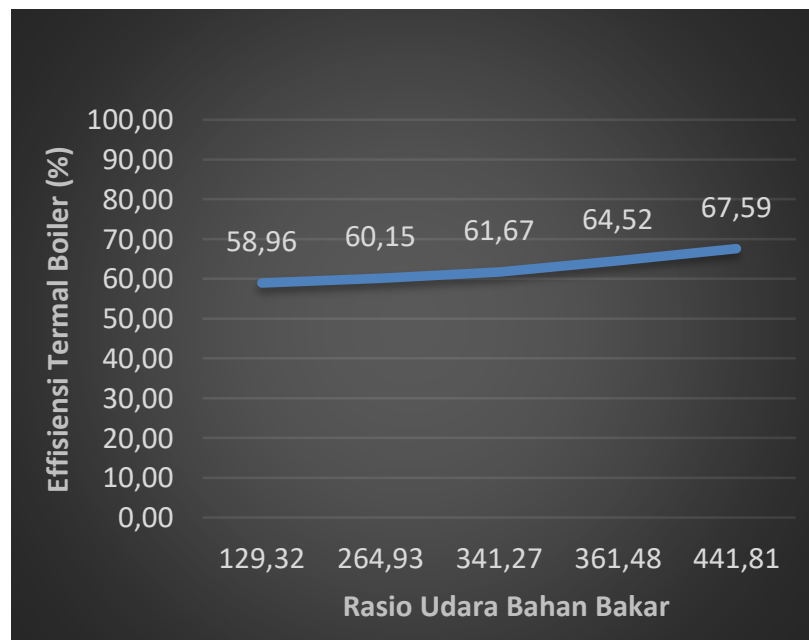

Gambar 7. Grafik Rasio Udara/BB Terhadap Effisiensi Termal Boiler (\%) 


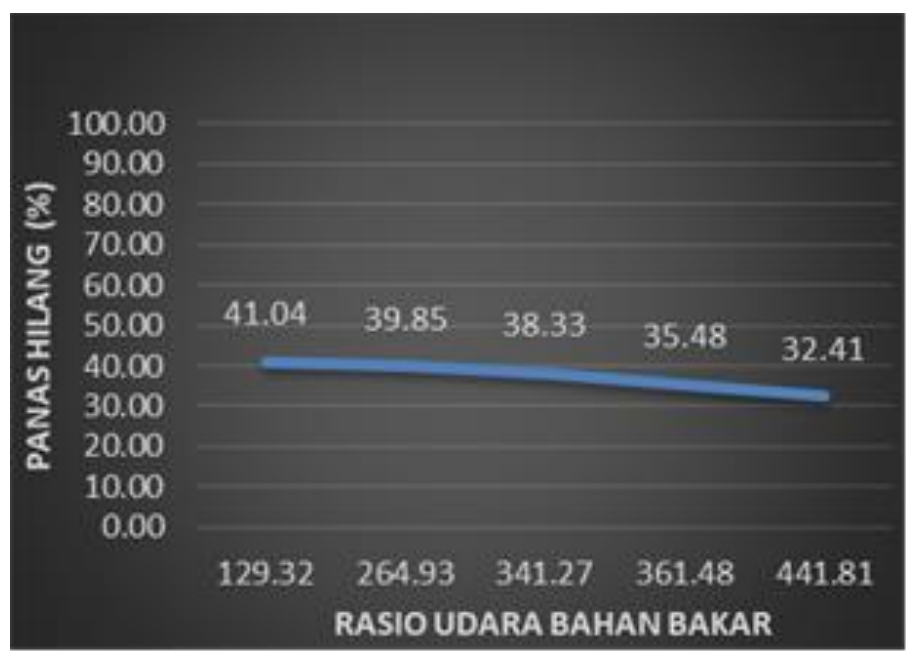

Gambar 8. Grafik Hubungan Rasio udara/BB Terhadap Kehilangan Panas (\%)

\section{KESIMPULAN}

Pada penelitian ini dapat disimpulkan bahwa effisiensi furnace pada double drum water tube boiler yang optimal pada rasio bahan bakar 361,48 dengan level ketinggan level volume 50\% pada proses superheated steam menggunakan bahan bakar LPG dengan effisiensi 64,52 \%, heat loss 35,48\%, udara excess $21 \%$. tekanan 5 bar temperatur $201^{\circ} \mathrm{C}$ dan pada proses superheated steam yang paling optimal pada rasio udara bahan bakar 17,57 menggunakan bahan bakar solar dengan efisiensi 62,15\%, heat loss 37,85\%, udara excess $18 \%$ tekanan 5 bar, dan temperatur $158,9^{\circ} \mathrm{C}$. Namun pada rasio 17,57 menggunakan bahan bakar solar dengan efisiensi $62,57 \%$, temperatur $158,9^{\circ} \mathrm{C}$ lebih kecil ketimbangan efisiensi dan temperature mengunakan bahan bakar gas LPG dikarenakan panas bahan LPG lebih bagus dibandingkan dengan solar sebab api yang dihasilkan di ruang bakar pembakaran warna biru yang menyebabkan panas yang dihasilkan lebih bagus dan pembakaran sempurna Pada rasio ke 361,48 bahan bakar LPG terjadi kenaikan efisiensi dan heat loss menurun sehingga pada proses pembakaran terjadi dengan sempurna karena kebanyakan panas termanfaatkan dari pada keluar terbuang, sehinga dikatkan optimal dengan apa yang di ingin dicapai pada penelitian ini.

\section{DAFTAR PUSTAKA}

[1] I. Muzaki and A. Mursadin, “Analisis Efisiensi Boiler Dengan Metode Input- Output Di Pt. Japfa Comfeed Indonesia Tbk. Unit Banjarmasin,” Sci. J. Mech. Eng. Kinemat., vol. 4, no. 1, pp. 37-46, 2019, doi: 10.20527/sjmekinematika.v4i1.50.

[2] S. Polmed, "Rancang Bangun Ketel Pipa Api Mini Kapasitas 8 Kg / Jam Dengan Tekanan 4 Bar," vol. 2, no. 1, 2021.

[3] Juriwon, “Analisis Energi Boiler Pipa Air Menggunakan Bahan Bakar Solar,” J. Has. Penelit. dan Ulas. Ilm., vol. 8, no. 2, pp. 7-13, 2017.

[4] P. N. Sriwijaya, "Pengaruh Rasio Udara Bahan Bakar Solar Dan Gas Terhadap Kualitas Saturated Steam Pada Sistem Two Drum Water Tube Boiler Effect Of Air Fuel Ratio Of Diesel And Gas Fuel On Saturated Steam Quality In The Two," vol. 11, no. 2, pp. 38-43, 2020.

[5] Y. D. Polewangi, "Analisis Sistem Perawatan Boiler di PT. Dewa Rencana Perangin-Angin," J. Ind. Manuf. Eng., vol. 2, no. 1, p. 29, 2019, doi: 10.31289/jime.v2i1.2428.

[6] S. Hidayanto, "Analisa Performa Water Tube Boiler Kapasitas 115 Ton/Jam di PT Pertamina Refinery Unit VI Balongan Indramayu," Skripsi. Semarang : UNNES, 2016.

[7] Y. Oktaviani, "Efisiensi Termal Produksi Steam Ditinjau Dari Rasio Udara Bahan Bakar Solar Pada Cross Section Water Tube Boiler,” vol. 12, no. 1, pp. 18-22, 2021.

[8] T. Pramona, N. U. Sari, and M. Septari, “Analisis Sistem Thermal Ditinjau Dari Rasio Udara Bahan Bakar Gas Lpg Terhadap Produksi Steam Pada Cross Section Water Tube Boiler The Analysis Of Thermal System Based On The Influence Of Lpg Gas Air Ratio On Steam Production Of Cross Section Water Tube B," no. x, pp. 1-5, 1978. 
[9] The American Society of Mechanical Engineers (ASME), "ASME boiler and pressure vessel code sec IX.," Asme, 2013.

[10] P. N. Sriwijaya, "Udara Bahan Bakar Solar Terhadap Produksi Saturated Dan Superheated Steam Pada Boiler The Analysis Of Thermal System Based On The Influence Of Diesel Air Ratio On Saturated And Siperheated Steam," vol. 12, no. 02, pp. 8-12, 2021. 